\title{
Influência do estágio supervisionado e do Programa Institucional de Bolsas de Iniciação à Docência (PIBID) na motivação de futuros professores de Biologia pela docência
}

\author{
The influence of supervised training and of the Institutional \\ Scholarship Program for Initial Teaching (PIBID) \\ on the motivation of future teachers of Biology
}

\author{
Camile Barbosa Moraes ${ }^{1}$. https://orcid.org/0000-0003-3267-4053 \\ Mara Eugênia Ruggiero de Guzzi² . https://orcid.org/0000-0001-9489-5105 \\ Luciana Passos Sá3 . https://orcid.org/0000-0003-0649-7938
}

\begin{abstract}
Resumo: Neste trabalho analisamos como as experiências formativas oferecidas por um curso de Licenciatura em Ciências Biológicas, com ênfase no Programa Institucional de Bolsas de Iniciação à Docência (PIBID) e Estágio Supervisionado motivaram os estudantes pela carreira docente na educação básica. Para tanto, a Teoria da Motivação da Autodeterminação foi adotada como referencial teórico. Os dados analisados são oriundos de narrativas autobiográficas de seis graduandos, obtidas a partir de entrevistas individuais, analisadas por meio da Análise Interpretativa. Nos resultados apresentamos e discutimos os principais elementos que motivaram ou desmotivaram os estudantes em ambas as experiências vivenciadas, resultando no maior ou menor interesse desses pela docência na Educação Básica.
\end{abstract}

Palavras-chave: Formação de professores. Estágio supervisionado. PIBID. Narrativa autobiográfica.

\begin{abstract}
In this paper, we examined how the formative experiences offered by an Undergraduate Program of Biological Sciences, with an emphasis on the Institutional Scholarship Program for Initial Teaching (Brazilian PIBID) and supervised training motivated students to pursue teaching careers in basic education. Thus, the Theory of Motivation of Self-Determination was adopted as a theoretical reference. The analyzed data come from autobiographical narratives by six undergraduate students, obtained from individual interviews, analyzed through Interpretative Analysis. In the results, we present and discuss the main elements that motivated or discouraged students in both experiences, resulting in the higher or lower interest of these students in teaching.
\end{abstract}

Keywords: Teacher training. Supervised training. PIBID. Autobiographical narrative.

\footnotetext{
${ }^{1}$ Universidade Estadual de Santa Cruz (UESC), Programa de Pós-graduação em Ensino de Ciências, Ilhéus, BA, Brasil. E-mail: camilemoraes2012@gmail.com

${ }^{2}$ Instituto Federal de Educação, Ciência e Tecnologia Baiano, Itapetinga, BA, Brasil.

${ }^{3}$ Universidade Federal de Santa Catarina (UFSC), Departamento de Química, Florianópolis, SC, Brasil.
} 


\section{Introdução}

A literatura especializada da área de ensino, mais especificamente aquela que se refere ao Ensino de Ciências, aponta que as vivências anteriores ao ingresso do estudante na Universidade (BERGAMASCHI; ALMEIDA, 2013; ROCHA, 2015), assim como as experiências formativas vivenciadas durante o curso de Licenciatura (BRACCINI, 2012; SOUZA, 2013) contribuem substancialmente para a construção da identidade profissional e exercem um papel decisivo no processo de decisão do indivíduo pela carreira docente.

Farias et al. (2009, p. 66) destacam que a formação docente se constitui como "um dos contextos de socialização que possibilita ao professor reconhecer-se como um profissional, construindo-se a partir de suas relações com os saberes e com o exercício da docência". Nesse sentido, entendemos que a formação inicial é de fundamental importância no processo de construção da identidade docente. Nesta etapa, o futuro professor tem a oportunidade de vivenciar experiências formativas em diferentes contextos e ambientes de ensino e participar de distintas atividades oferecidas pela universidade, dentre as quais se destacam os projetos de iniciação à docência, os estágios obrigatórios e não-obrigatórios, os projetos de iniciação científica e as disciplinas voltadas ao ensino.

Considerando que estas múltiplas vivências podem motivar ou desmotivar o licenciando pela atividade docente, neste trabalho nos propusemos a analisar o impacto de ações praticadas na formação inicial na promoção da motivação, mais especificamente, aquelas desenvolvidas no âmbito do estágio supervisionado obrigatório e do Programa de Bolsa de Iniciação à Docência (PIBID). Buscaremos entender como tais atividades influenciaram o fluxo motivacional dos licenciandos, analisando particularidades de cada uma das experiências, considerando ainda a complexidade e a diversidade com que essas são desenvolvidas nos distintos contextos em que ocorrem.

Cabe destacar que o presente estudo trata-se de um recorte de uma pesquisa mais ampla de Moraes (2017), que discute o papel da formação inicial e a importância das histórias de vida na identificação dos aspectos motivacionais de futuros professores.

\section{Motivação na formação de professores}

A palavra motivação deriva do latim movere, que significa motivo. Neste sentido, motivo ou motivação é aquilo que move um indivíduo ou que o põe em ação ou o faz alterar a direção (BZUNECK, 2009). Segundo Severo (2014, p. 13), a motivação trata-se de "um processo psicológico no qual interagem as características de personalidade e as características ambientais percebidas".

Para Reeve (2006) a palavra motivação pode ser definida como o processo que orienta e energiza o comportamento dos indivíduos. Segundo o autor, os principais aspectos capazes de promover este comportamento são os motivos internos (necessidades, cognições, emoções) e os eventos externos. Nesta perspectiva, Ryan e Deci (2000) defendem que, embora a motivação seja considerada um constructo singular, os indivíduos podem ser motivados a desenvolverem uma tarefa por diferentes fatores, dentre eles: valorização de uma atividade, coerção externa, interesse permanente, por suborno ou medo. 
A motivação humana tem se destacado como um campo de análise da Psicologia. De acordo com Cernev (2011) há diferentes conceitos e teorias para explicar o termo motivação, provenientes de distintas abordagens: Cognitiva, Sociocognitiva, Behaviorista, Humanista e Psicanalítica. No cenário educacional, as abordagens teóricas mais amplamente empregadas nas pesquisas sobre motivação fundamentam-se, prioritariamente, na perspectiva Cognitiva e Sociocognitiva.

Os estudos acerca da motivação pautados na abordagem sociocognitiva priorizam tanto a quantidade como a qualidade da motivação. Segundo Severo (2014), este tipo de abordagem reconhece a importância das interferências sociais na ocorrência dos comportamentos. Dentre as teorias sociocognitivas que contribuem para o entendimento da qualidade da motivação se destacam a Teoria da Autodeterminação, a Teoria de Metas de Realização e o Autoconceito. Neste estudo utilizaremos como referencial teórico a Teoria da Autodeterminação (TAD).

A TAD foi inicialmente proposta em 1985 por dois psicólogos norte-americanos, Edward L. Deci e Richard M. Ryan e, posteriormente, refinada por estudiosos de diversos países. Nos últimos anos, a teoria tem sido utilizada em pesquisas desenvolvidas em diferentes áreas de estudo, tais como Educação, Psicoterapia, Psicopatologia, Esporte e Saúde. Segundo Ryan e Deci (2000), na maioria das pesquisas a TAD é empregada com o objetivo de analisar os fatores ambientais que impedem, ou comprometem, a motivação autodeterminada, o funcionamento social e o bem-estar dos indivíduos.

Com efeito, a TAD propõe a consideração, no processo do desenvolvimento humano e orientação motivacional, de três necessidades psicológicas básicas: competência, autonomia e relacionamento, conforme ilustra a Figura 1.

Figura 1 - Necessidades psicológicas básicas da motivação
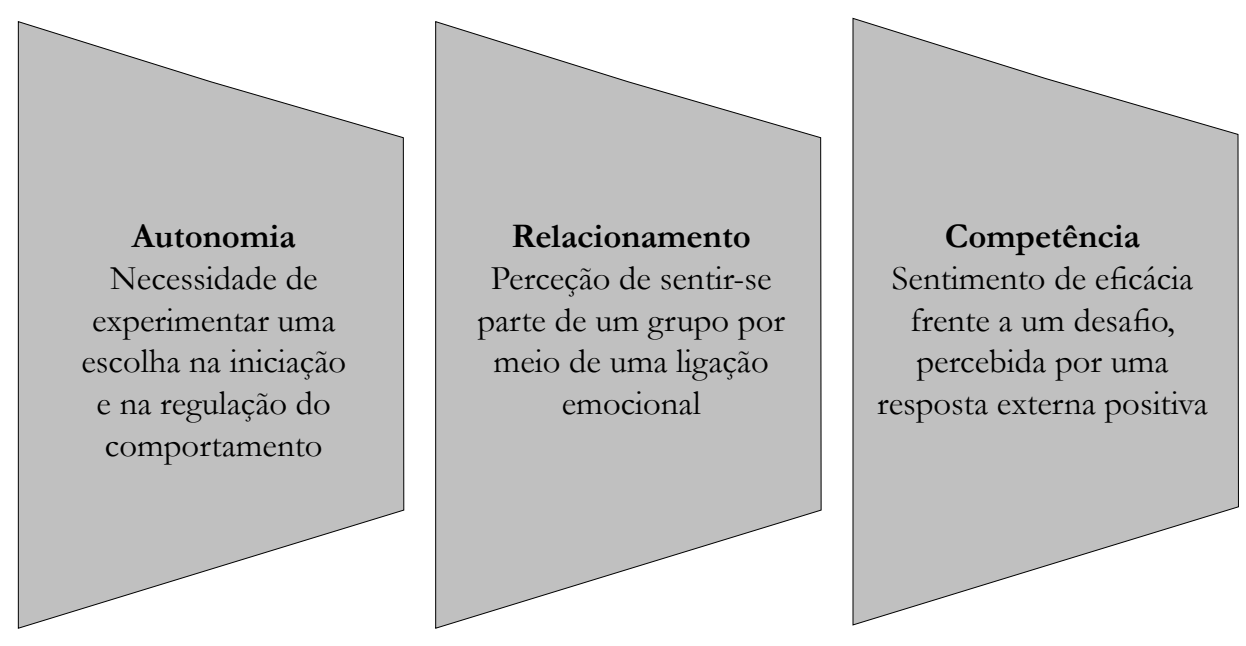

Fonte: adaptado de Reeve (2006). 
Esta teoria propõe que os ambientes e interações que propiciam a satisfação de tais necessidades fundamentais estimulam o desenvolvimento saudável do organismo e a autoregulação, favorecendo, desta forma, o deslocamento para formas autodeterminadas da motivação (DECI; RYAN, 2008; GUIMARÃES; BZUNECK, 2008).

As necessidades psicológicas ilustradas na Figura 1 são aspectos essenciais no estudo sobre a motivação do comportamento humano. A análise dessas necessidades psicológicas inatas auxilia na compreensão sobre como os indivíduos estabelecem suas interações com o ambiente e de que forma eles conseguem se adaptar, transformar e desenvolver em virtude dessas alterações. Baseado nesse entendimento é possível afirmar que tanto o indivíduo quanto o ambiente estão, sucessivamente, passando por transformações (REEVE, 2006). Dessa forma, o contexto, a região sociogeográfica na qual os sujeitos encontram-se inseridos, e as relações estabelecidas no ambiente escolar são determinantes para a escolha profissional do indivíduo.

No que diz respeito às pesquisas que correlacionam a motivação com as narrativas autobiográficas, destacamos a realizada por Cunha (2015), que buscou compreender e investigar narrativas autobiográficas de docentes do curso de Letras-Inglês da Universidade Estadual do Piauí. O estudo envolveu iniciantes do magistério superior, com foco nas experiências formadoras vivenciadas antes do exercício da profissão docente e no início da carreira. Além disso, o autor analisa a motivação destes professores para o ingresso na carreira docente.

No âmbito da pesquisa educacional, existem trabalhos que investigam a motivação de alunos e professores, nos diferentes níveis de ensino, sob o olhar da Teoria da Autodeterminação. Almeida (2012), por exemplo, analisou a motivação de estudantes de ensino superior de instituições públicas e privadas, de diversas regiões do país. A autora constatou que os discentes valorizam cursos que proporcionam crescimento pessoal e que contribuem para a qualificação técnica. Além disso, verificou-se que as mulheres e alunos mais velhos apresentaram níveis mais autônomos de motivação.

Martinelli e Sisto (2010) analisaram a motivação intrínseca e extrínseca de 617 estudantes matriculados no terceiro, quarto e quinto anos do ensino fundamental de seis escolas brasileiras. Os autores observaram, dentre outros aspectos, que houve uma redução gradativa da motivação extrínseca dos estudantes à medida em que estes avançavam nos anos escolares. Este resultado evidenciou a necessidade da realização de mais pesquisas sobre a orientação motivacional dos alunos, tanto do ponto de vista individual, quanto coletivo.

Cabe salientar que os estudos fundamentados na Teoria da Autodeterminação ainda são incipientes na literatura nacional. Desse modo, no presente trabalho temos a intenção de avaliar o perfil motivacional de professores em formação inicial a partir de narrativas autobiográficas. As narrativas permitem o acesso a informações sobre aspectos pessoais, culturais, sociais e profissionais dos indivíduos e podem fornecer elementos importantes para a compreensão de aspectos relacionados à motivação dos licenciandos pela carreira docente.

\section{O estágio supervisionado e o PIBID}

O estágio supervisionado obrigatório já não é o único espaço para que os licenciandos vivenciem a realidade da sala de aula da educação básica. Nos últimos anos, tem sido oferecida aos estudantes dos cursos de licenciatura de instituições de ensino superior brasileiras, a oportunidade de vivenciarem a realidade escolar por meio de atividades formativas diversas, 
desenvolvidas no âmbito do Programa Institucional de Bolsa de Iniciação à Docência (PIBID). Ambos os espaços têm sido objeto de estudo por pesquisadores da área educacional. Sá e Garritz (2015), por exemplo, sinalizam para a importância das experiências vivenciadas nestes espaços formativos, no processo de construção dos saberes necessários à docência, e para a contribuição destas na promoção da motivação de futuros professores pela profissão.

O Estágio Supervisionado é um componente curricular obrigatório nos cursos de licenciatura de instituições de ensino superior brasileiras, sendo considerado essencial para a formação inicial de professores, visto que concede ao licenciando a oportunidade de inserir-se no campo profissional, de articular teoria à prática, e de enfrentar os desafios da prática docente. Neste momento o futuro professor vivencia experiências pedagógicas e "conhece melhor sua área de atuação e tem a oportunidade de aplicar os conhecimentos teóricos adquiridos" (ROSA; WEIGERT; SOUZA, 2012, p. 678).

Nesse contexto, numerosos estudos evidenciam que o estágio supervisionado pode representar um espaço favorável para o desenvolvimento de pesquisas, de reflexão sobre a prática pedagógica, de construção da identidade profissional, troca de saberes com a comunidade escolar, assim como ressignificação de saberes inerentes à profissão docente (BARBOSA, 2013; MACIEL, 2012). Há também estudos que apontam para as principais tensões e desafios enfrentados pelos futuros professores durante o estágio supervisionado, dentre os quais destacam-se: indisciplina dos alunos, desvalorização profissional, desmotivação dos estudantes em aprender os conteúdos ministrados, problemas com a infraestrutura e aspectos físicos das escolas e a inexperiência dos licenciandos para lidar com diferentes situações em sala de aula (MASSABNI, 2011; USTRA; HERNANDES, 2010).

O PIBID, por outro lado, apresenta como objetivo a inserção de alunos dos cursos de licenciatura plena no cotidiano de escolas da rede pública de educação básica, como forma de oportunizar a criação e participação destes indivíduos em experiências metodológicas, tecnológicas e práticas docentes de caráter inovador e interdisciplinar (BRASIL, 2007). As ações propostas pelo PIBID não se limitam à sala de aula, mas abrangem o envolvimento dos bolsistas na organização e gestão do espaço escolar. Dessa forma, os licenciandos que participam do Programa também aprendem que "as relações interpessoais, a humildade, o planejamento coletivo e a gestão compartilhada são indispensáveis para o sucesso de qualquer escola” (FREITAG et al., 2012, p. 74).

Em relação aos impactos do PIBID na formação inicial de professores e suas contribuições para a construção da identidade docente, um número significativo de pesquisas tem sido realizado no cenário educacional brasileiro. Torres et al. (2013), por exemplo, verificaram que o Programa contribuiu satisfatoriamente para a formação de futuros professores de Biologia, uma vez que permitiu a superação de visões simplistas do docente, assim como a construção da identidade do professor crítico-reflexivo. Soares (2012, p. 45) destaca que a participação dos bolsistas “[...] nas práticas escolares possibilita uma troca de experiências que são qualitativamente e quantitativamente mais expressivas que o estágio curricular”. Esses espaços formativos, apesar de se aproximarem em muitos aspectos, possuem distintas configurações, com particularidades e contextos que os tornam mais, ou menos capazes de motivar os licenciandos pela carreira docente na educação básica. Nesse sentido, Martins, Farias e Cavalcanti (2012) mencionam que os bolsistas, ao apresentarem suas vivências, acabam por comparar as experiências do PIBID com as vivências do estágio supervisionado. Em seus relatos os alunos afirmam que o pouco tempo destinado à vivência da sala de aula, no contexto do estágio, acaba por ser um fator 
limitante na identificação com a profissão. Na perspectiva desses alunos, tal limite é superado pelo PIBID, uma vez que o período de contato com a escola é maior.

Neste trabalho buscaremos indícios da motivação dos futuros professores proporcionadas pela vivência nestas duas experiências, evidenciadas no processo de reflexão por meio das narrativas autobiográficas, conforme discutido no próximo tópico.

\section{Professor reflexivo e narrativas autobiográficas}

A prática reflexiva crítica é apontada por diversos pesquisadores como um aspecto que merece ser incentivado na formação inicial e continuada de professores, visto que esta dimensão formativa possibilita a aprendizagem, construção e ressignificação de saberes e ações inerentes à profissão, assim como a compreensão da complexidade do trabalho docente (PIMENTA, 2008; ZEICHNER, 2008). De acordo com Zeichner (2008), o movimento da prática reflexiva advoga que os docentes precisam participar ativamente na elaboração e planejamento dos propósitos do seu trabalho, colaborando com o desenvolvimento do conhecimento acerca do ensino. Nesse sentido, o autor evidencia a importância de estabelecer conexões entre reflexão docente e lutas por justiça social, visto que a reflexão é um ato político e todas as ações de ensino possuem implicações pessoais, acadêmicas e políticas.

Tendo em vista a polissemia do termo reflexão, que tem assumido diferentes conotações por aqueles que o utiliza, conforme discute Zeichner (2008), cabe esclarecer que, neste trabalho, a ação reflexiva a que nos referimos "implica uma consideração ativa, persistente e cuidadosa daquilo em que se acredita ou que se pratica, à luz dos motivos que o justificam e das conseqüências a que conduz" (DEWEY, 1993 apud ZEICHNER, 1993, p. 18). Desse modo, empregamos a Narrativa Autobiográfica, estratégia que tem sido discutida na literatura e usada por formadores de professores nos cursos de licenciatura com o intuito de estimular a prática reflexiva. Segundo Reis (2008), a narrativa é um importante método de investigação científica, capaz de auxiliar na construção de saberes e desenvolvimento pessoal e profissional docente. Além disso, estudos apontam que as narrativas baseadas nas trajetórias de vida são estratégias capazes de evidenciar a influência de elementos motivacionais na escolha profissional dos indivíduos (BOHNEN, 2011; SOUZA, 2004) e permite identificar informações relevantes sobre a influência dos diferentes contextos e das condições sócio geográficas em que o sujeito encontra-se imerso. Estes aspectos são determinantes para a compreensão da motivação dos sujeitos no alcance dos seus objetivos, assim como na definição do desempenho destes no ambiente (ALMEIDA, 2012). Nessa direção, Souza (2006) aponta as principais características deste instrumento de investigação/formação: "[...] as dimensões autoformativas e ecoformativas que emergem da narrativa de formação ligam-se à globalidade da vida e das experiências pessoal, profissional, cultural, social, espiritual, encarando a formação como um trabalho e atividade do sujeito sobre si e em relação a si mesmo, aos outros e aos diferentes espaço-tempos em que está inserido" (SOUZA, 2006, p. 39).

Segundo Farias et al. (2009), a história de vida do professor é composta pelas suas raízes sociais, experiências escolares, influências da família e de outros grupos com os quais se compartilha uma cultura. Em outras palavras, o professor se produz por meio das relações que estabelece com o mundo físico e social. Ainda, de acordo com os autores, o professor não é apenas um profissional, mas uma pessoa formada, parcialmente, pelos valores da sua profissão 
e por outros valores e aprendizagens provenientes do contexto político, econômico e cultural de onde ele cresce e se desenvolve.

No que diz respeito ao uso das narrativas autobiográficas na formação inicial de professores, merece destaque a pesquisa desenvolvida por Silva (2014), que teve por objetivo compreender o processo de formação inicial de licenciandos no contexto do estágio supervisionado, no movimento da escrita narrativa. A autora verificou que a escrita do memorial de formação estimulou o aluno-estagiário do curso de licenciatura a refletir criticamente sobre as aprendizagens vivenciadas que foram essenciais para a sua formação, em uma dinâmica em que este se reinventa, recriando-se pessoal, profissional e intelectualmente.

\section{Percurso metodológico}

Esta pesquisa possui abordagem qualitativa. De acordo com Richardson (1999, p. 80), estudos dessa natureza "podem descrever a complexidade de determinado problema, analisar a interação de certas variáveis, compreender e classificar processos dinâmicos vividos por grupos sociais". Neste estudo optamos por utilizar o Método (Auto) biográfico, caracterizado por Galvão (2005) como:

[...] uma forma simultaneamente rica, exaustiva e difícil de investigação. Rica em termos de experiência humana, pelas interações que se estabelecem entre todas as pessoas envolvidas, exaustiva pelo necessário aprofundamento e diversidade de estratégias para coleta de informação e difícil pela conjugação necessariamente coerente de todos os elementos passíveis de análise (GALVÃO, 2005, p. 341).

O presente trabalho foi desenvolvido em uma universidade pública do Estado da Bahia. Participaram da pesquisa seis discentes do curso de Licenciatura em Ciências Biológicas, selecionados com base nos seguintes critérios: ter integralizado pelo menos $50 \%$ das disciplinas obrigatórias do curso; estar regularmente matriculado no curso; ter cursado pelo menos uma disciplina de Estágio Supervisionado; mostrar disponibilidade para participar da pesquisa. Metade dos participantes deveria estar matriculada no período diurno, e a outra metade, no período noturno. O trabalho foi aprovado por Comitê de Ética e atende a todas as exigências da pesquisa com seres humanos.

Neste estudo, as informações foram obtidas por meio de entrevista narrativa individual, do tipo oral, com os seis licenciandos. Estas entrevistas foram gravadas em áudio, seguiram um roteiro previamente estabelecido e tiveram como objetivo favorecer a compreensão acerca, principalmente, dos seguintes aspectos: escolha pela profissão docente; influência das experiências vivenciadas durante a infância, assim como o papel de ex-professores nesse processo; importância das experiências formativas vivenciadas no curso de Licenciatura em Ciências Biológicas. Sobre este último versa o presente trabalho.

Cabe ressaltar que a pesquisa não esteve vinculada a nenhuma disciplina oferecida pelo curso. O contato com os participantes foi feito em horário extraclasse. Após a realização das entrevistas as falas dos licenciandos foram transcritas e, posteriormente, analisadas. 
O instrumento de análise das informações utilizado na pesquisa foi a técnica de Análise Interpretativa, proposta por Souza (2004). A Análise Interpretativa caracteriza-se como uma noção metafórica de leitura, a qual decompõe o trabalho em três tempos, a saber: o Tempo I, no qual é feita uma pré-análise do material; o Tempo II, no qual são efetuadas as leituras temáticas e a construção de categorias; e o Tempo III, conhecida como leitura interpretativo-compreensiva do corpus. Segundo o autor esses três momentos de análise sustentam em si uma relação de harmonia e diálogo contínuo.

Dessa maneira, buscamos indícios do favorecimento das necessidades psicológicas de autonomia, competência e relacionamento, fundamentais para a regulação de comportamentos autodeterminados, de acordo com a teoria da Motivação da Autodeterminação (DECI; RYAN, 2008). Cabe ressaltar que os sujeitos da pesquisa são referenciados por códigos alfanuméricos, visando com isso preservar as suas identidades. Assim, os licenciandos serão chamados pela sigla LC seguida por números (LC1 a LC6).

\section{Resultados e discussão}

A pré-análise das informações obtidas por meio das narrativas autobiográficas possibilitou conhecer o perfil dos seis participantes deste estudo, no que diz respeito a gênero, idade, turno e semestre letivo cursado na ocasião das entrevistas.

Quadro 1 - Perfil dos licenciandos participantes da pesquisa

\begin{tabular}{|l|l|l|l|l|l|l|}
\hline \multirow{2}{*}{\multicolumn{1}{c|}{ Dados }} & \multicolumn{7}{c|}{ Licenciandos } & \multicolumn{1}{c|}{ LC6 } \\
\cline { 2 - 7 } & \multicolumn{1}{|c|}{ LC1 } & \multicolumn{1}{c|}{ LC2 } & LC3 & LC4 & LC5 & \multicolumn{1}{c|}{ LC } \\
\hline Idade & 25 anos & 24 anos & 28 anos & 23 anos & 22 anos & 24 anos \\
\hline Gênero & Feminino & Masculino & Feminino & Feminino & Feminino & Feminino \\
\hline Turno & Noturno & Noturno & Noturno & Diurno & Diurno & Diurno \\
\hline Semestre Letivo & $9^{\circ}$ & $9^{\circ}$ & $9^{\circ}$ & $8^{\circ}$ & $8^{\circ}$ & $8^{\circ}$ \\
\hline
\end{tabular}

Fonte: Elaborado pelas autoras.

A partir dos dados apresentados no Quadro 1 verificamos que a faixa etária dos licenciandos envolvidos neste estudo varia entre 22 e 28 anos. São, portanto, estudantes que ingressaram ainda muito jovens na Universidade. Todos os participantes já concluíram mais de $75 \%$ das disciplinas do curso e, dentre elas, pelo menos uma disciplina de Estágio Supervisionado obrigatório, os Módulos Interdisciplinares para o Ensino de Biologia (Prática como Componente Curricular), Metodologia para o Ensino de Ciências e Metodologia para o Ensino de Biologia. Dos seis participantes da pesquisa, cinco são do sexo feminino e apenas quatro atuaram como bolsistas no PIBID.

A seguir apresentamos fragmentos das narrativas autobiográficas dos licenciandos, mais precisamente aqueles que apontam para a motivação (ou desmotivação) pela carreira docente, proporcionada pelas experiências formativas vivenciadas durante o curso de graduação, com ênfase no Estágio Supervisionado e PIBID. Na discussão dos dados empregaremos a Teoria da Autodeterminação, proposta por Deci e Ryan (1985). 


\section{Estágio Supervisionado}

O Estágio Supervisionado é uma importante fase da formação inicial de professores, visto que permite ao estudante do curso de licenciatura refletir e construir (ou desconstruir) expectativas sobre a profissão docente e sobre o "ser professor" (PIMENTA; LIMA, 2010).

No que se refere às contribuições do estágio supervisionado para a motivação dos licenciandos pela atuação na docência, três deles mencionam que as experiências vivenciadas neste ambiente os desmotivaram a atuarem como professores de Biologia na Educação Básica. Segundo eles, os estágios foram marcados por momentos de dificuldades, dúvidas e problemas de relacionamento com os alunos e professor regente.

No terceiro estágio, aí sim en já fiquei muito frustrado, porque eu tive problema de comunicação com a professora regente e com os alunos. [LC2, grifo nosso].

As disciplinas de Estágio Supervisionado não foram muito boas para mim. Assim, no primeiro estágio eu fui para uma turma de alunos do Fundamental II, numa turma de sexto ano. Foi uma experiência que me marcou, primeiro porque você chega no Estágio e o licenciando fica um curto período de tempo com uma turma que já tem um bom entrosamento com o professor regente. O licenciando é novato, então para ele conquistar a confiança e o respeito daqueles alunos é difícil, porque você não conquista de uma hora para outra, o professor regente está ali há mais tempo, já o licenciando chegou naquele ambiente agora. [LC3, grifo nosso].

Minha experiência no Estágio III não foi tão boa, en peguei uma turma de primeiro ano. Os alunos eram invocados e eu tive um pouco de dificuldade com a indisciplina deles, pois eu estava acostumada com alunos tranquilos, em que en falava e eles me obedeciam, Eles conversavam, pois o aluno não ébrincadeira também, né? Mas nesse periodo eu tive um problema porque as alunas não gostavam de mim. (LC4, grifo nosso).

Entendemos as questões de relacionamento destacadas nas falas de LC2, LC3 e LC4 como a "necessidade de estabelecer vínculos com outros indivíduos, refletindo o desejo de estar vinculado e envolvido de forma emocional e interpessoal em relacionamentos atenciosos e respeitosos" (SEVERO, 2014, p. 23). Verifica-se que a boa relação do professor regente com a turma, mencionada por LC3, não parece influenciar na receptividade dos estagiários por parte estudantes, que são vistos como estranhos naquele ambiente. Para LC2, a dificuldade de comunicação e relacionamento com o professor regente e com a turma foram fatores externos que o desmotivou pela carreira docente na Educação Básica.

Por outro lado, dois licenciandos mencionam aspectos positivos da experiência vivenciada no Estágio Supervisionado, relativas ao relacionamento entre licenciando e estudantes da Educação Básica, assim como entre licenciandos e professores regentes.

No estágio I eu tive um choque muito grande, porque você ter ido para a sala de aula, só ouvindo aqui na universidade algumas orientaçoes sobre o que a gente tem 
que fazer na escola... E no Estágio é você que manda, vamos dizer assim, você que tem o poder de direcionar os alunos. Como a gente passa por um período de observação, então foi bem importante essa experiência para mim. Ter conhecido a turma de alunos, ter estabelecido uma relação boa com a professora supervisora. E ai eu fui tentando me adaptar e o saldo foi positivo. [LC1, grifo nosso].

O Estágio III foi bom, en fiquei em turma com alunos do Ensino Médio. A relação que eu tive foi mais tranquila. A professora regente ficou presente na sala de aula, nas duas primeiras semanas de aula quando a gente estava observando e depois deixou a gente meio que na sala sozinhos. Mas aí a gente já tinha mais experiência e os alunos nos respeitavam mais, vamos dizer assim, os alunos conseguiram enxergar nós, estagiários, como professores, como alguém que estava ali para ensinar coisas novas e para aprender com eles também. [LC5, grifo nosso].

De acordo com Reeve (2006, p. 77), o relacionamento pode ser descrito como "um constructo motivacional importante, porque quando as relações interpessoais apoiam os indivíduos em sua necessidade de relação, eles têm um desempenho melhor, apresentam maior resistência ao estresse e relatam ter menos dificuldades psicológicas”. Sendo assim, é imprescindível que o futuro professor tenha oportunidade de participar de experiências formativas em que se estabeleça um bom relacionamento com a comunidade escolar (gestores, coordenadores pedagógicos, professores, alunos, pais, comunidade, secretários etc.) e com isso desenvolva capacidades e habilidades importantes para a superação dos desafios educacionais.

Estudos recentes acerca do Estágio Supervisionado, dentre os quais destacamos o de Castoldi e Polinarski (2009), apontam que a maioria dos licenciandos percebe o estágio como um momento de tomada de decisão sobre ser ou não ser professor, visto que é nesta etapa que estes vivenciam os problemas da escola e passam a conhecer o papel de educador. Nesse sentido, LC5 ressalta a importância dos Estágios Supervisionados para a definição de suas carreiras e desenvolvimento da necessidade psicológica básica de competência.

A experiência que eu tive no Estágio II já foi um pouco melhor. Eu tive uma professora que estava fazendo o trabalho dela de Doutorado com a perspectiva CTS, então ela explicou um pouco sobre o CTS. E ela propôs que nós fizéssemos uma proposta didática baseada nessa perspectiva e usando um tema da Biologia. Ai, o nosso grupo trabalhou com o tema Água. Foi muito bom porque a gente pôde ver a escola de uma forma diferente.

Nós apresentamos o nosso projeto em uma escola estadual e depois a gente apresentou em outros lugares também, em eventos científicos, como o Encontro Regional de Ensino de Biologia. O nosso experimento foi uma mini estação de tratamento de água. Ai, depois disso, quem viu e gostou falou com a gente, e pediu para que nós fossemos lá na escola deles, pois iria ter a Semana em comemoração ao Dia da Água: - Por que vocês não apresentam lá? [LC5, grifo nosso].

Constatamos que o desenvolvimento da proposta didática mencionada por L5, no âmbito do Estágio Supervisionado, nutriu um sentimento de competência, entendida neste 
estudo como a capacidade de o ser humano interagir de maneira eficiente com o ambiente social, assim como desenvolver habilidades e talentos (GUIMARÃES, 2009). No âmbito da motivação humana, a competência pode ainda ser definida como "uma necessidade psicológica que fornece uma fonte inerente de motivação capaz de fazer as pessoas buscarem algo e se esforçarem para alcançar o que for necessário para dominar desafios" (REEVE, 2006, p. 73). $\mathrm{O}$ autor ressalta ainda que determinadas condições podem satisfazer a necessidade de competência ou então desfavorecê-la.

LC1 e LC2 sinalizam ainda que a ausência de autonomia no espaço escolar é um aspecto negativo vivenciado durante o Estágio.

Eu acho que as disciplinas de Estágio Supervisionado são muito importantes para o curso de licenciatura em Biologia, porque a gente passa o tempo todo vendo a teoria. Eu acho que o Estágio é o momento de pôr em prática toda a teoria vivenciada e tudo que a gente aprendeu. Para mim foi de grande valia a disciplina de Estágio, apesar de que os professores da disciplina de Estágio cobram muito dos licenciandos, mas esse é o papel deles. A gente tem que buscar várias coisas diferentes $e$ às vežes, o Colégio e os alunos em si não nos permite fazer algumas coisas que foram planejadas. [LC1, grifo nosso].

A questão da autonomia, que sempre é falada aqui na universidade, ai quando eu cheguei lá na escola, vi que não tive autonomia em sala de aula. [LC2, grifo nosso].

Segundo Reeve (2006), a promoção da necessidade de autonomia "depende bastante do grau de apoio e de satisfação (grau de apoio à sua autonomia) versus o grau de indiferença e de frustração (grau de controle) com que suas relações com o ambiente são percebidas" (REEVE, 2006, p. 81). Nessa perspectiva, a motivação pode ser enfraquecida quando a instituição escolar e o professor regente não permitem ações autônomas por parte do licenciando. Desse modo, faz-se necessário oferecer mais liberdade e apoio para a tomada de decisões relacionadas à prática pedagógica dos professores em formação inicial.

\section{Programa Institucional de Bolsa de Iniciação à Docência}

O PIBID é um programa que visa a valorização da profissão docente e incentiva a iniciação à docência por meio de ações didático-pedagógicas que aproximam o licenciando da realidade escolar. Segundo Sartori (2011) o Programa consiste em uma iniciativa criada para fortalecer a formação de professores, por meio de uma maior articulação entre os saberes construídos na universidade e os saberes que, cotidianamente, são produzidos na escola. Nessa direção, alguns trabalhos reportados na literatura apontam que o PIBID tem apresentado resultados satisfatórios, tanto no âmbito escolar como para a formação docente (DINIZ et al., 2013; PAZZINATTO et al., 2013).

O PIBID foi mencionado pelos quatro licenciandos que dele participaram como importante motivador para o exercício da docência. Segundo eles, o Programa possibilitou maior aproximação com a realidade da escola e com a prática da sala de aula, dentre outras 
razões pela convivência com a professora regente, considerada por LC3 como um exemplo de profissional a ser seguido.

Então, o PIBID me motivou a permanecer na docência. O PIBID foi aquela oportunidade que eu tive de acompanhar um professor em exercício, alguém mais experiente. Então, o acompanbamento que eu fiz também com uma professora, excelente profissional. Eu acho que ela é um exemplo de professora, porque ela buscava transmitir esse conhecimento e independente das dificuldades ela queria exercer o papel dela. Então, o PIBID durante esses dois anos que en fui bolsista, me aproximou de uma realidade diferente. Momento em que eu pude ter um contato com um professor experiente, ver os pontos positivos, ver os pontos negativos. [LC3, grifo nosso].

Para LC3, a interação e a troca de experiências entre os licenciandos e a professora supervisora, proporcionadas pelo PIBID, é um ponto considerado importante na formação do futuro professor. De acordo com Farias (2012) o professor supervisor possui conhecimentos autênticos e, por essa razão, é capaz de auxiliar e promover a aprendizagem dos futuros docentes. O Programa oferece a oportunidade de o licenciando participar do planejamento de todas as ações e com base na reflexão e discussão com todos os envolvidos no processo sobre as experiências vivenciadas (licenciandos, professor supervisor e coordenador) replanejar o ensino. No que se refere a reflexão-na-ação, Schön (1992) assinala que depois da aula, o docente "pode pensar no que aconteceu, no que observou, no significado que lhe deu e na eventual adoção de outros sentidos. Refletir sobre a reflexão-na-ação é uma ação, uma observação e uma descrição, que exige o uso de palavras" (SCHÖN, 1992, p. 83). Todos estes aspectos se traduzem em desafios para a formação docente.

De acordo com o relato de LC4, o PIBID favoreceu a necessidade psicológica de autonomia e competência.

O PIBID me proporcionou muito mesmo. Está ali na sala de aula, por mais que a gente não venha a dar aula, de fato, aula teórica, mas nós ministramos a aula prática. Então, é muito bom, muito bom! E mesmo assim com o último edital nós fomos autorizados a dar aulas teóricas, só que mediante a presença do professor supervisor. Então, por exemplo, no ano passado, na verdade eu nem sei se foi no edital passado, mas enfim, no ano passado, eu ministrei uma aula teórica sobre Vírus, usando até modelos didáticos. Foi bem legal! [LC4, grifo nosso].

A autonomia para a elaboração da aula teórica, assim como para a escolha e utilização de estratégias didáticas diferenciadas (modelo didático), despertou em LC4 o sentimento de competência e valorização no desenvolvimento de habilidades inerentes à sala de aula. De acordo com Reeve (2006) no momento em que o ser humano atua de forma autônoma "o comportamento emana de um lócus interno de causalidade percebido, dando ao indivíduo uma sensação de liberdade e a percepção de que seu comportamento desenrolou-se a partir de ações por ele próprio escolhidas" (REEVE, 2006, p. 81). Resultado semelhante foi encontrado no trabalho desenvolvido por Oliveira, Nogueira e Reges (2012), ao perceberam que as aulas ministradas 
pelos participantes do PIBID favoreceram o desenvolvimento da segurança e da autonomia para o exercício da futura profissão.

No que tange à competência, de acordo com Reeve (2006, p. 81) esta necessidade psicológica promove no ser humano a vontade de "desenvolver-se, melhorar e apurar suas habilidades e seus talentos pessoais". Observamos o favorecimento desta necessidade psicológica quando LC4 demonstra satisfação ao relatar sobre o processo de preparação de aulas e elaboração de materiais didáticos.

A fala de LC5 abaixo ressalta as contribuições do PIBID para a construção da sua identidade profissional, visto que o programa permitiu a vivência de diferentes aspectos da atividade docente.

O PIBID tem me motivado a permanecer na carreira docente, porque ele me ajudou a conhecer mais a escola, conhecer mais a vivência do professor em sala de aula. Porque a gente conhecia a escola enquanto aluno, só que através do PIBID foi que eu conheci os bastidores que eu, enquanto aluno, não conbecia, ou seja, toda aquela parte que diz respeito ao trabalho do professor. Então, o PIBID me possibilitou ficar mais desinibida em relação a chegar numa sala de aula e desenvolver aquela atividade com os alunos. Então, o PIBID, porque eu comecei a fazer o PIBID antes de comecar os estágios, foi essencial para mim. Tanto que quando eu cheguei nos estágios eu não sentia tanto medo assim, porque tudo isso foi sendo quebrado, os meus medos foram sendo retirados sem traumas com o PIBID. [LC5, grifo nosso].

Os dados analisados apontam que o PIBID desempenha um importante papel no processo de permanência dos licenciandos no curso, visto que propicia a articulação entre a escola e a universidade, além daquela já propiciada pelo Estágio Supervisionado. Além disso, a experiência proporcionada pelo Programa contribui na preparação do licenciando para enfrentar os desafios do Estágio Supervisionado, conforme menciona LC5.

A partir dos dados analisados verifica-se que o PIBID é visto, pelos licenciandos, como mais significativo para a formação docente, se comparado ao estágio supervisionado. Frustação, problemas de relacionamento e indisciplina, tempo insuficiente, falta de autonomia, são aspectos mencionados pelos licenciandos ao refletirem sobre o Estágio. Diante disso tecemos algumas considerações sobre as duas experiências formativas:

- a presença de um supervisor, incentivado financeira e pedagogicamente para atuar junto aos licenciandos é um aspecto que favorece significativamente o bom desempenho das ações realizadas no âmbito do PIBID;

- o tempo dedicado às ações do PIBID é, frequentemente, maior que o tempo destinado à realização do estágio, favorecendo a aproximação do licenciando com o professor supervisor e a sua familiarização com a escola e sua realidade. Esse tempo é essencial para que o licenciando conquiste a confiança e o respeito dos estudantes e aprenda a melhor lidar com a questão da indisciplina;

- A autonomia na sala de aula é um aspecto que varia de acordo com o contexto, sendo o PIBID e o Estágio espaços igualmente capazes de promover condições de autonomia para que os licenciandos desenvolvam suas habilidades profissionais;

- A postura e as crenças do professor e do licenciando frente às ações propostas é 
outro fator determinante para o bom aproveitamento das experiências e, consequentemente, da motivação que proporcionam, sejam elas desenvolvidas no âmbito do Estágio ou do PIBID.

- Pesquisas que discutem o estágio supervisionado sinalizam que a escola parece não entender a sua corresponsabilidade nesse processo de formação inicial (AGOSTINI; TERRAZAN, 2012). Diante deste quadro, concordamos com Silva e Schnetzler (2008) quando apontam para a necessidade de políticas públicas na educação brasileira que melhor definam o papel que as escolas devem assumir/atribuir na formação inicial dos professores, assim como do "papel dos licenciandos nas escolas; organização do tempo e espaços mais adequados a uma lógica que propicie uma vivência maior das situações escolares" (SILVA; SCHNETZLER, 2008, p. 2182).

Segundo Tardif (2000) o professor é um ator social e seus pensamentos e ações carregam consigo as marcas do contexto no qual está inserido. Isso nos leva a crer que o PIBID e o Estágio podem ser experiências igualmente motivadoras e profícuas na formação dos licenciandos, mas que são fortemente influenciadas pelo contexto e pelas crenças dos sujeitos nelas envolvidos.

\section{Considerações finais}

A partir da análise realizada verificamos que o estágio supervisionado proporcionou aos licenciandos diferentes impactos na formação e motivação para o exercício da profissão docente. Para alguns estagiários o desenvolvimento das necessidades psicológicas de relacionamento e de autonomia foi favorecido pela participação no estágio, enquanto que outros enfatizam dificuldades de relacionamento entre licenciando e estudantes e/ ou professor regente, proporcionado pelo tempo destinado ao estágio e pela forma como esse vem sendo praticado. Segundo estes, o estágio causou a desmotivação pelo curso e, consequentemente, o pouco interesse pela profissão docente, sendo uma experiência frustrante para aqueles que necessitavam de maior apoio nesta etapa formativa. Acreditamos que a necessidade de relacionamento é favorecida em alguns casos e em outros não pelo fato de o estágio ocorrer em distintos espaços, com distintos professores regentes, que podem ou não contribuir para a motivação do estudante pela docência.

Em contrapartida, no PIBID o professor supervisor (regente) é previamente selecionado e incentivado, com apoio técnico e financeiro, a participar da formação do futuro professor, a partir do acompanhamento e participação ativa em todas as ações realizadas no âmbito da sala de aula. Esse vínculo estabelecido entre professor regente e licenciando, propiciado pelo Programa, fortemente evidenciado nas narrativas, é um fator que, indiscutivelmente, contribui para o desenvolvimento das necessidades psicológicas básicas da motivação. Além disso, o maior tempo de atuação do licenciando na escola, enquanto participante do PIBID, é essencial para que as necessidades de relacionamento e autonomia sejam satisfeitas.

Apesar de os resultados apresentados apontarem o PIBID como uma experiência mais motivadora, se comparada ao Estágio Supervisionado, é preciso considerar que estes dados são baseados nas experiências vivenciadas pelos participantes desta pesquisa e, portanto, não nos permitem fazer generalizações sobre a eficiência destes dois espaços formativos. 
Influência do estágio supervisionado e do Programa Institucional ...

\section{Agradecimentos}

Agradecemos o apoio concedido pela Fundação de Amparo à Pesquisa do Estado da Bahia (FAPESB).

\section{Referências}

AGOSTINI, S.; TERRAZZAN, E. A. O estágio curricular supervisionado na UFSM: o trabalho docente no ensino superior. Diálogo Educacional, Curitiba, v. 12, n. 37, p. 977-995, 2012. DOI: https://doi.org/10.7213/dialogo.educ.7213.

ALMEIDA, D. M. S. A motivação do aluno no ensino superior: um estudo exploratório. 2012. Dissertação (Mestrado em Educação) - Universidade Estadual de Londrina, Londrina, 2012.

BARBOSA, N. F. M. O estágio na formação inicial de professores no ensino de língua inglesa. 2013. Dissertação (Mestrado) - Universidade Federal de Ouro Preto. Instituto de Ciências Humanas e Sociais, Ouro Preto, 2013.

BERGAMASCHI, M. A.; ALMEIDA, D. B. Memoriais escolares e processos de iniciação à docência. Educação em Revista, Belo Horizonte, v. 29, n. 2, p. 15-41, 2013. DOI: https:// doi.org/10.1590/S0102-46982013000200002.

BOHNEN, N. T. A jornada do herói: a narrativa autobiográfica na construção da identidade profissional do professor. 2011. Dissertação (Mestrado) - Faculdade de Letras, Universidade Federal de Goiás, Goiânia, 2011.

BRACCINI, M. L. A iniciação científica e o exercício da docência na educação básica: ressignificações da experiência de professores iniciantes. 2012. Dissertação (Mestrado em Educação) - Escola de Humanidades, Universidade do Vale do Rio dos Sinos, São Leopoldo, 2012.

BRASIL. Portaria normativa $n^{\circ} 38$, de 12 de dezembro de 2007. Dispõe sobre o Programa de Bolsa Institucional de Iniciação à Docência - PIBID. Diário Oficial da União: seção 1, Brasília, DF, n. 239, p. 39, 13 dez. 2007. Disponível em: https://www.capes.gov.br/images/ stories/download/legislacao/Portaria_Normativa_38_PIBID.pdf. Acesso em: 6 fev. 2019.

BZUNECK, J. A. A motivação do aluno: aspectos introdutórios. In: BORUCHOVITCH, E.; BZUNECK, J. A. (org.). A motivação do aluno: contribuições da psicologia contemporânea. 4. ed. Petrópolis, RJ: Vozes, 2009. p. 9-36.

CASTOLDI, R.; POLINARSKI, C. A. Considerações sobre estágio supervisionado por alunos licenciandos em ciências biológicas. In: ENCONTRO NACIONAL DE PESQUISA EM EDUCAÇÃO EM CIÊNCIAS, 7., Florianópolis, 2009. Anais [...]. Florianópolis: ABRAPEC, 2009. Disponível em http://posgrad.fae.ufmg.br/posgrad/viienpec/. Acesso em: 6 fev. 2019.

CERNEV, F. K. A motivação de professores de música sob a perspectiva da teoria da autodeterminação. 2011. Dissertação (Mestrado em Música) - Instituto de Artes, Universidade Federal do Rio Grande do Sul, Porto Alegre, 2011. 
CUNHA, R. C. O ingresso no ensino superior e a escolha pelo curso de letras-inglês: narrativas autobiográficas de professores iniciantes na UESPI. In: ENCONTRO INTERREGIONAL NORTE, NORDESTE E CENTRO-OESTE SOBRE FORMAÇÃO DOCENTE PARA EDUCAÇÃO BÁSICA E SUPERIOR, 6., e ENCONTRO INTERNACIONAL SOBRE A FORMAÇÃO DOCENTE PARA EDUCAÇÃO BÁSICA E SUPERIOR, 1, 2015, Brasília, DF. Anais [...]. Brasília: EdunB, 2015.

DECI, E. L.; RYAN, R. M. Intrinsic motivation and self-determination in human behavior. New York: Plennum Press, 1985.

DECI, E. L.; RYAN, R. M. Self-determination theory: a macrotheory of human motivation, development, and health. Canadian Psychology, Washington, v. 49, n. 3, p. 182-185, 2008. DOI: https://doi.org/10.1037/a0012801.

DINIZ, F. M. B.; RODRIGUES, F. R.; OLIVEIRA, M. L. B.; ALVES, E. L. Criatividade e ludicidade nas oficinas do PIBID de história e geografia: "a casa" tecendo a cidadania. In: SALÃO DE ENSINO E DE EXTENSÃO, 4., 2013, Santa Cruz do Sul. Anais [...]. Santa Cruz do Sul: UNISC, 2013.

FARIAS, I. M. S.; SALES, J. O. C. B.; BRAGA, M. M. S. C.; FRANÇA, M. S. L. M. Didática e docência: aprendendo a profissão. Brasília: Liber Livro, 2009.

FARIAS, I. M. S. O que move professores a aprender?: significados e implicações do PIBID na formação continuada. In: ENCONTRO NACIONAL DE DIDÁTICA E PRÁTICAS DE ENSINO, 16., 2012, Campinas. Anais [...]. Campinas: Unicamp, 2012.

FREITAG, D. et al. PIBID: Programa de iniciação à docência, conquistas e desafios. Unoesc \& Ciência - ACHS, Joaçaba, p. 69-79, 2012. (Edição especial). Disponível em: https:/ / portalperiodicos.unoesc.edu.br/index.php/achs/article/view/2432. Acesso em: 7 fev. 2019.

GALVÃO, C. Narrativas em educação. Ciência \& Educação, Bauru, v. 11, n. 2, p. 327-345, 2005. DOI: https://doi.org/10.1590/S1516-73132005000200013.

GUIMARÃES, S. E. R. Motivação intrínseca, extrínseca e o uso de recompensas em sala de aula. In: BORUCHOVITCH, E.; BZUNECK, J. A. (org.). A motivação do aluno: contribuições da psicologia contemporânea. 4. ed. Petrópolis, RJ: Vozes, 2009. p. 37-57.

GUIMARÃES, S. E. R.; BZUNECK, J. A. Propriedades psicométricas de um instrumento para a avaliação da motivação de universitários. Ciências \& Cognição, Rio de Janeiro, v. 13, n. 1, p. 101-113, mar. 2008. Disponível em: http://www.cienciasecognicao.org/revista/index. $\mathrm{php} / \mathrm{cec} / \mathrm{article} / \mathrm{view} / 682 / 459$. Acesso em: 7 fev. 2019.

MACIEL, E. M. O estágio supervisionado como espaço de construção do saber ensinar. 2012. Dissertação (Mestrado em Educação) - Fundação Universidade Federal do Piauí, Teresina, 2012.

MARTINELLI, S. C.; SISTO, F. F. Motivação de estudantes: um estudo com crianças do ensino fundamental. Avaliação Psicológica, São Paulo, v. 9, n. 3, p. 413420, dez. 2010. Disponível em: http://pepsic.bvsalud.org/scielo.php?script=sci_ arttext\&pid=S1677-04712010000300008. Acesso em: 7 fev. 2018. 
Influência do estágio supervisionado e do Programa Institucional ...

MARTINS, M. M. C.; FARIAS, I. M. S.; CALVACANTI, M. M. D. Nos caminhos entre o estágio supervisionado e o PIBID: o que contam os licenciandos de biologia? In: ENCONTRO NACIONAL DE DIDÁTICA E PRÁTICAS DE ENSINO, 16., 2012, Campinas. Atas [...]. Campinas: Unicamp, 2012.

MASSABNI, V. G. Os conflitos de licenciandos e o desenvolvimento profissional docente. Educação e Pesquisa, São Paulo, v. 37, n. 4, p. 793-808, dez. 2011. DOI: https://doi. org/10.1590/S1517-97022011000400008.

MORAES, C. B. A motivação pela docência: narrativas autobiográficas de professores de biologia em formação inicial. 2017. Dissertação (Mestrado em Educação em Ciências) - Departamento de Ciências Exatas e Tecnológicas, Universidade Estadual de Santa Cruz, Ilhéus, 2017.

OLIVEIRA, F. G. O.; NOGUEIRA L. M. L.; REGES, M. A. G. Contribuições do PIBID para a construção da identidade profissional docente: concepções de bolsistas do curso de pedagogia. In: FÓRUM INTERNACIONAL DE PEDAGOGIA, 4., 2012. Anais [...]. Campina Grande: Realize, 2012.

PAZZINATTO, L. B.; BORGES, V. A.; REIS, J. S.; REZENDE, S. O.; SILVA, R. A. O. Visita didático-pedagógica: uma parceria entre escola e universidade. In: ENCONTRO ESTADUAL DE DIDÁTICA E PRÁTICAS DE ENSINO, 5., 2013, Goiânia. Anais [...]. Goiânia: UFG, 2013.

PIMENTA, S. G. Professor reflexivo: construindo uma crítica. In: PIMENTA, S. G.; GHEDIN, E. (org.). Professor reflexivo no Brasil: gênese e crítica de um conceito. 5. ed. São Paulo: Cortez, 2008. p. 17-52.

PIMENTA, S. G.; LIMA, M. S. L. Estágio e docência. 5. ed. São Paulo: Cortez, 2010.

REEVE, J. Motivação e emoção. 4. ed. Rio de Janeiro: LTC, 2006.

REIS, P. R. As narrativas na formação de professores e na investigação em educação.

Nuances: Estudos sobre Educação, Presidente Prudente, ano 14, v. 15, n. 16, p. 17-34, jan./ dez. 2008. DOI: https://doi.org/10.14572/nuances.v15i16.174.

RICHARDSON, R. J. Pesquisa social: métodos e técnicas. 3. ed. São Paulo: Atlas, 1999.

ROCHA, R. N. O conhecimento pedagógico do conteúdo de professores de química e suas trajetórias de vida: possíveis relações. 2015. Dissertação (Mestrado em Educação em Ciências) - Universidade Estadual de Santa Cruz, Ilhéus, 2015.

ROSA, J. K. L.; WEIGERT, C.; SOUZA, A. C. G. A. Formação docente: reflexões sobre o estágio curricular. Ciência \& Educação, Bauru, v. 18, n. 3, p. 675-688, 2012. DOI: https:// doi.org/10.1590/S1516-73132012000300012.

RYAN, R. M.; DECI, E. L. Self-determination theory and the facilitation of intrinsic motivation, social development, and well-being. American Psychologist, v. 55, n. 1, p. 6878, 2000. DOI: https://doi.org/10.1037/0003-066X.55.1.68. 
SÁ, L. P.; GARRITZ, A. Perspectiva de estudantes de química sobre uma proposta de produção e aplicação de unidades didáticas e o impacto do PIBID na formação docente. Química Nova na Escola, São Paulo, v. 37, n. 3, p. 187-196, 2015. DOI: https://doi. org/10.5935/0104-8899.20150038.

SARTORI, J. Formação de professores: conexões entre saberes da universidade e fazeres na educação básica. In: ENCONTRO INSTITUCIONAL DO PIBID, 2., 2011, Porto Alegre. Anais [...]. Porto Alegre: UFRGS, 2011.

SCHÖN, D. A. Formar professores como profissionais reflexivos. In: NÓVOA, A (org). Os professores e a sua formação. Lisboa: Publicações Dom Quixote, 1992. p. 77-91.

SEVERO, I. R. M. Levantamento do perfil motivacional de alunos do ensino médio de três escolas públicas da cidade de São Carlos/SP, na disciplina de química. 2014. Dissertação (Mestrado em Química) - Instituto de Química, Universidade de São Paulo, São Carlos, 2014.

SILVA, A. V. Memorial de formação: dispositivo de pesquisa-formação no/do estágio supervisionado. 2014. Tese (Doutorado em Educação e Contemporaneidade) - Universidade do Estado da Bahia, Salvador, 2014.

SILVA, R. M. G.; SCHNETZLER, R. P. Concepções e ações de formadores de professores de química sobre o estágio supervisionado: propostas brasileiras e portuguesas. Química Nova, São Paulo, v. 31, n. 8, 2008. DOI: https://doi.org/10.1590/S010040422008000800045.

SOARES, M. N. O estágio curricular supervisionado na licenciatura em ciências biológicas e a busca pela experiência formativa: aproximações e desafios. 2012. Tese (Doutorado em Educação para a Ciência) - Faculdade de Ciências, Universidade Estadual Paulista Júlio de Mesquita Filho, Bauru, 2012.

SOUZA, E. C. O conhecimento de si: estágio e narrativas de formação de professores. Rio de Janeiro: DP\&A; Salvador: UNEB, 2006.

SOUZA, E. C. O conhecimento de si: narrativas do itinerário escolar e formação de professores. 2004. Tese (Doutorado em Educação) - Universidade Federal da Bahia, Salvador, 2004.

SOUZA, L. N. O estágio supervisionado no curso de licenciatura em ciências biológicas na Universidade Federal de Goiás, campus Goiânia. 2013. Dissertação (Mestrado em Educação em Ciências e Matemática) - Universidade Federal de Goiás, Goiânia, 2013.

TARDIF, M. Saberes profissionais dos professores e conhecimentos universitários. Revista Brasileira de Educação, Rio de Janeiro, n. 13, p. 5-23, 2000. Disponível em: http://anped. tempsite.ws/novo_portal/rbe/rbedigital/RBDE13/RBDE13_05_MAURICE_TARDIF.pdf. Acesso em: 7 fev. 2019. 
TORRES, C. M. G.; SILVA, M. M. F.; FERNANDES, A. M.; LAURINDO, J. I. O. Formação do professor de biologia: uma análise a partir do Programa Institucional de Bolsa de Iniciação à Docência (PIBID). Revista Interfaces: saúde, humanas e tecnologia, Juazeiro do Norte, v. 1, n. 1, p. 1-18, 2013. Disponível em: http://interfaces.leaosampaio.edu.br/index.php/revistainterfaces/article/view/9/pdf. Acesso em: 7 fev. 2019.

USTRA, S. R. V.; HERNANDES, C. L. Enfrentamento de problemas conceituais e de planejamento ao final da formação inicial. Ciência \& Educação, Bauru, v. 16, n. 3, p. 723-733, 2010. DOI: https://doi.org/10.1590/S1516-73132010000300015.

ZEICHNER, K. M. A formação reflexiva de professores: idéias e práticas. Lisboa: Educa, 1993.

ZEICHNER, K. M. Uma análise crítica sobre a "reflexão" como conceito estruturante na formação docente. Educação e Sociedade, Campinas, v. 29, n. 103, p. 535-554, 2008. DOI: https://doi.org/10.1590/S0101-73302008000200012. 
